\title{
Parametrical network models of distribution of limited resources in difficult systems
}

\author{
Vadim Belousov ${ }^{1, *}$, Irina Fateeva ${ }^{1}$ and Antonina Deniskina $^{2}$ \\ ${ }^{1}$ Voronezh State Technical University, Moscow Avenue, 14, Voronezh, 394026, Russia \\ ${ }^{2}$ Moscow Aviation Institute, Volokolamskoe highway, 4, Moscow, 125993, Russia
}

\begin{abstract}
In article effective methods of the temporary analysis and calculation of the generalized network models are offered. On their basis the class of parametrical network models is under construction and applications of such models to problems of distribution of limited resources of difficult systems in the conditions of an intensification of works are considered. A number of terms of scheduling is specified. Conditions of consistency and criteria of resource resolvability of some classes of tasks on such models are investigated.
\end{abstract}

\section{Introduction}

Wide use of stream algorithms on networks, in particular on the generalized network models, is caused by a number of the reasons from which it is possible to distinguish the following [1]. Algorithms provide fast convergence in comparison with the general methods of linear programming, solve a multicriteria problem, find plans not only meeting Pareto's condition, but also not improved by one of criteria, allow a huge number of the modifications allowing not only to accelerate convergence, but also to find the plans meeting various vector criteria [2].

Methods and algorithms of the temporary analysis are widely put into practice. In this article the general problem definition of the temporary analysis the formalized description of a wide class of algorithms of search of plans of early and late terms is offered, and also new assessment of number of iterations is given.

\section{Problem definition}

1. Let $X$ - the final set, $x \in X$ is interpreted as the identifier of an event $x, U$ - a final set of communications (arches), $\Theta$ - space of plans - the functions set on $X$.

If $T, T^{\prime} \in \Theta$ and $T_{x} \leq T_{x}$ ` for all $x \in X$, then we write $T \leq T^{\prime}$.

Functions 1 and $\mathrm{L} \in \Theta, 1 \leq \mathrm{L}$ and function $\alpha$ on a set of $\mathrm{U}$ are set.

Definition $1^{\circ}$. The plan of $\mathrm{T}$ we will call consistent in touch $(\mathrm{x}, \mathrm{y}) \in \mathrm{U}$ if

$$
\mathrm{T}_{\mathrm{x}}+\alpha_{\mathrm{xy}} \leq \mathrm{T}_{\mathrm{y}} .
$$

\footnotetext{
*Corresponding author: belousov@vgasu.ru
} 
Definition $2^{\circ}$. We will call the plan of $\mathrm{T}$ to the satisfying early directive restrictions if

$$
1<\mathrm{T}
$$

and to late directive restrictions, if

$$
\mathrm{T} \leq \mathrm{L}
$$

Among plans, consistent on all communications and satisfying to both early, and late directive restrictions, are looked for such which deliver an extremum to the linear $\mathrm{f}(\mathrm{T})$ form or the vector linear $F(T)=(F 1(T) \ldots, f m(T))$.

It is known that if a set $\Theta_{1}$ admissible (ratios (1), (2), (3) are executed) plans of a task are not empty, there are two plans of $T_{*}, T^{*} \in \Theta_{1}$, called respectively by plans of early and late terms, such that

$$
\mathrm{T} *<\mathrm{T}<\mathrm{T}^{*}
$$

for any $\mathrm{T} \in \Theta_{1}$.

The plan of early terms minimizes a vector linear form

$$
\mathrm{T}_{\mathrm{x}} \rightarrow \min \text { for all } \mathrm{x} \in \mathrm{X} \text {. }
$$

The similar statement is fair for the plan of late terms:

$$
\mathrm{T}_{\mathrm{x}} \rightarrow \max \text { for all } \mathrm{x} \in \mathrm{X} \text {. }
$$

$\mathrm{T}$ * we do not improve the plan of $\mathrm{T}$ by one of criteria of $\mathrm{T}_{\mathrm{x}}$. Thanks to it the vector criterion can be curtailed in scalar in shape

$$
\sum_{x \in X} \lambda_{x} T_{x} \rightarrow \min .
$$

where $\lambda_{\mathrm{x}}$ - any set positive numbers (in particular, they can equal to unit). For $\mathrm{T} *$ we will have:

$$
\sum_{x \in X} \lambda_{x} T_{x} \rightarrow \max
$$

The criterion (4) is linear therefore for finding of the plan of early terms it is possible to use methods of linear programming, for example, a simplex method.

If the plan of $\mathrm{T}$, then its duration $\tau$ is set is defined as follows:

$$
\tau=\max _{x, y \in X}\left|T_{x}-T_{y}\right|
$$

It is known [3] that the plan of short deadlines is called the plan of the minimum duration. The problem of search of plans of short deadlines is not linear, however it can be linearized by introduction of two fictitious events $\xi$ and $\eta(\tilde{X}=X \cup\{\xi\} \cup\{\eta\})$ and additions to a set $\mathrm{U}$ communications of a $\operatorname{look}(\xi, \mathrm{x})$ and $(\mathrm{x}, \eta)$ for $\mathrm{x} \in \mathrm{X}$, and to ratios (1) inequalities

$$
\begin{array}{ll}
\mathrm{T}_{\xi} \leq \mathrm{T}_{\mathrm{x}}, & \mathrm{x} \in \mathrm{X}, \\
\mathrm{T}_{\mathrm{x}} \leq \mathrm{T}_{\eta}, & \mathrm{x} \in \mathrm{X} .
\end{array}
$$

Now the task of search of plans of short deadlines is set as a problem of minimization of linear criterion of $\mathrm{f}=\mathrm{T}_{\eta}-\mathrm{T}_{\xi}$. This task as well as the problem of search of plans of early and late terms, can be solved by methods of linear programming. 
However more effective in this case are the stream algorithms which are going back to Ford [3,4]. If concerning a set of $U$ there is no additional information, then the most expedient stream algorithm is "Pendulum" (by search of plans of short deadlines the algorithm "Pendulum" is applied three times).

\section{Algorithm of finding of the plan of early terms}

Very often the set $U$ communications can be presented in the form of association of some characteristic subsets of $\mathrm{V}_{\mathrm{i}} \subset \mathrm{U}$. Process of creation of the plan begins with the plan 1 which, as a rule, is not admissible since for some communications the condition is not satisfied (1). This plan is gradually corrected, i.e. the estimated moments of a fulfillment of events increase by some rule. Namely, as soon as it is found out that for (x, y) $\in \mathrm{U}$ of inequalities (1) is not executed, value of the plan on an event at increases and becomes equal to the left part of inequality (1). Thus, in the course of correction terms of a fulfillment of events of the current plan increase.

Considering all this, we will consider various mathematical objects connected with any set of $\mathrm{V} \subset \mathrm{U}$ and any "directive" early terms of $\mathrm{T}^{\circ} \geq 1$.

Definition $3^{\circ}$. For $\mathrm{V} \subset \mathrm{U}$ and $\mathrm{T}^{\circ} \geq 1$ we will call 1 plan of $\mathrm{T}\left(\mathrm{V}, \mathrm{T}^{\circ}\right)$ - we will allow if $\mathrm{T} \geq \mathrm{T}^{\circ}$ and inequality (1) is executed for all $(\mathrm{x}, \mathrm{s}) \in \mathrm{V}$.

Definition $4^{\circ}$. For $\mathrm{V} \subset \mathrm{U}$ and $\mathrm{T}^{\circ} \geq 1$ we will call 1 plan of $\mathrm{T}$ the plan $\left(\mathrm{V}, \mathrm{T}^{\circ}\right)$ - early terms if the $\mathrm{T}$ is $\left(\mathrm{V}, \mathrm{T}^{\circ}\right)$ - admissible and $\mathrm{T} \leq \mathrm{T}_{1}$ for any $\left(\mathrm{V}, \mathrm{T}^{\circ}\right)$ - the admissible plan of $\mathrm{T}$ we Will designate $\mathrm{T}$

$$
T=\bar{V} T^{\circ}
$$

The operator $\bar{V}$ we will call the operator of early terms corresponding to a set of $\mathrm{V} \subset \mathrm{U}$. Properties o $\{\bar{V}\} V \subset U$ f family of operators:

1. (idempotence) $\bar{V}^{2}=\bar{V}$;

2. (double monotony) if $\mathrm{V}_{1} \subset \mathrm{V}_{2}$ and $\mathrm{T}^{(1)} \leq \mathrm{T}^{(2)}$, then $\bar{V}_{1} T^{(1)}=\bar{V}_{2} T^{(2)}$;

3. $\bar{V}_{2} \bar{V}_{1} \leq \bar{V}_{1} \cup \bar{V}_{2}$.

4. The $\varnothing$ operator is single: $\varnothing \mathrm{T}=\mathrm{T}$.

Statement 1 . If $\mathrm{V}$ consists of one communication $(\mathrm{y}, \mathrm{z})$

$$
(\{(y, z)\} T)_{x} \equiv(\bar{V} T)_{x}=\left\{\begin{array}{l}
T_{x}, \quad \text { if } \quad x \neq z \\
\max \left\{T_{x}, T_{y}+\alpha_{x y}\right\}, \text { if } x=z
\end{array}\right.
$$

In this case $\bar{V}$ is the elementary operator changing the plan of T no more than for one event of z. Generally $\bar{V}$ is the work of elementary operators.

Let's designate through $G(V)$ a set of the ways consisting of elements of a set of $V$, integrated with a set of fictitious ways of a look $(x, x)$ zero length.

Let final point of $\mathrm{xq}$ of a way $\gamma_{1}=\left(\mathrm{h}_{1} ; \mathrm{h}_{2} \ldots, \mathrm{x}_{\mathrm{q}}\right)$ coincides with the initial point of a way $\gamma_{2}=\left(\mathrm{x}_{\mathrm{q}} ; \mathrm{x}_{\mathrm{q}+1} \ldots, \mathrm{x}_{\mathrm{m}}\right)$. Let's designate through $\gamma_{1}, \gamma_{2}$ the integrated way

$$
\gamma_{1} \gamma_{2}=\left(h_{1} ; h_{2} \ldots, x_{\mathrm{q}}, \mathrm{x}_{\mathrm{q}+1}, \ldots, \mathrm{x}_{\mathrm{m}}\right) \text {. }
$$

Multiplication of ways has property of associatively: the work of several ways $\gamma_{1}, \gamma_{2} \ldots$ $\gamma_{\mathrm{k}}$ does not depend on arrangement of brackets.

For $\mathrm{V}_{1} \ldots, \mathrm{V}_{\mathrm{k}}$ we will designate through $\mathrm{G}\left(\mathrm{V}_{1}, \ldots, \mathrm{V}_{\mathrm{k}}\right)$ set of ways of a look $\gamma=\gamma_{\mathrm{i} 1}, \gamma_{\mathrm{i} 2}$, $\ldots \gamma_{\mathrm{im}}$, where $\gamma_{\mathrm{ij}} \mathrm{V}_{\mathrm{ij}} ; 1 \leq \mathrm{i}_{1}<\mathrm{i}_{2}<\ldots<\mathrm{i}_{\mathrm{m}} \leq \mathrm{k}$.

Statement 2. $\mathrm{G}\left(\mathrm{V}_{\mathrm{i} 1}, \mathrm{~V}_{\mathrm{i} 2}, \ldots, \mathrm{V}_{\mathrm{im}}\right) \subset \mathrm{G}\left(\mathrm{V}_{1}, \mathrm{~V}_{2}, \ldots, \mathrm{V}_{\mathrm{k}}\right)$ For any subsequence of indexes $1<\mathrm{i}_{1}<\mathrm{i}_{2}<\ldots<\mathrm{i}_{\mathrm{m}}<\mathrm{k}$. 
Let's designate through $G_{n}\left(V_{1} \ldots, V_{k}\right)$ set of ways of a .vid $\gamma=\gamma_{1}, \gamma_{2}, \ldots \gamma_{m}, m \leq n$, where $\gamma_{\mathrm{i}} \in \mathrm{G}\left(\mathrm{V}_{1}, \mathrm{~V}_{2}, \ldots, \mathrm{V}_{\mathrm{k}}\right), \mathrm{m} \leq \mathrm{n} \mathrm{n}$.

Lemma 1 . For any $\mathrm{V}_{1}, \ldots, \mathrm{V}_{\mathrm{k}}$ will be such $\mathrm{n}$ that $\mathrm{G}_{\mathrm{n}}\left(\mathrm{V}_{1}, \mathrm{~V}_{2} \ldots, \mathrm{V}_{\mathrm{k}}\right)$ contains all ways without cycles belonging to a $\operatorname{set} G\left(\bigcup_{i=1}^{k} V_{i}\right)$.

Let's designate through $\mathrm{S}\left(\mathrm{V}_{1} \ldots, \mathrm{V}_{\mathrm{k}}\right)$ the minimum number $\mathrm{n}$ meeting a condition of the previous lemma.

Let's notice that the sequence of $\mathrm{G}_{\mathrm{n}}\left(\mathrm{V}_{1}, \ldots, \mathrm{V}_{\mathrm{k}}\right), \mathrm{n} \geq 1$ is extending on inclusion, contained, nevertheless, century $G\left(\stackrel{k}{U} V_{i=1}\right)$. This sequence gradually joins not only ways without cycles, but also ways with cycles.

Therefore

$$
\bigcup_{n=1}^{\infty} G_{\eta}\left(V_{1}, \ldots, V_{k}\right)=G\left(\bigcup_{n=1}^{\infty} V_{i}\right)
$$

i.e. sets $\mathrm{G}_{\mathrm{n}}\left(\mathrm{V}_{1}, \mathrm{~V}_{2} \ldots, \mathrm{V}_{\mathrm{k}}\right)$ exhaust all set $G\left(\stackrel{k}{U_{i=1}} V_{i}\right)$.

For $\mathrm{V} \subset \mathrm{U}$ we will designate through $\mathrm{A}(\mathrm{V})$ and $\mathrm{B}(\mathrm{V})$ of a set initial (x) and according to final (y) events for all communications $(\mathrm{x}, \mathrm{y}) \in \mathrm{V}$. For $\mathrm{V}_{1}, \mathrm{~V}_{2} \in \mathrm{U}$ we will designate

$$
\mathrm{C}\left(\mathrm{V}_{1}, \mathrm{~V}_{2}\right)=\mathrm{B}\left(\mathrm{V}_{2} \mid \mathrm{V}_{1},\right) \cap \mathrm{A}\left(\mathrm{V}_{1}\right) \text {. }
$$

Lemma 2. For any $\mathrm{V}_{1}, \mathrm{~V}_{2} \subset \mathrm{U}$ the following assessment takes place:

$$
\mathrm{s}\left(\mathrm{V}_{1}, \mathrm{~V}_{2}\right) \leq\left|\mathrm{C}\left(\mathrm{V}_{1}, \mathrm{~V}_{2}\right)\right|+1 \text {. }
$$

Sequence of sets of $\mathrm{y}_{\mathrm{b}} \ldots$, we will call $\mathrm{У}_{\kappa}$ unilateral if at any $\mathrm{i}=1 \ldots, \mathrm{k}$ a $\operatorname{set} C\left(\bigcup_{j=1}^{i-1} V_{j}, V_{i}\right)$ is empty.

Lemma 3. If $\mathrm{V}_{1}, \ldots, \mathrm{V}_{\mathrm{k}}$ - the unilateral sequence, then $\mathrm{S}\left(\mathrm{V}_{1}, \ldots, \mathrm{V}_{\mathrm{k}}\right)=1$.

Theorem 1. ${ }_{i=1}^{\bar{k} V_{i}}=\left(\bar{V}_{k}, \ldots, \bar{V}_{1}\right)^{n}$ at any $\mathrm{n} \geq \mathrm{s}\left(\mathrm{V}_{1}, \ldots, \mathrm{V}_{\mathrm{k}}\right)$.

The theorem is a direct consequence of a lemma 2.

Investigation 1. If

$$
\begin{gathered}
\left(\bar{V}_{k} \ldots \bar{V}_{1}\right)^{\eta+1} T^{\circ}, \\
\text { that } \overline{\bigcup_{i=1}^{k} V_{i} T^{\circ}}=\left(\bar{V}_{k} \ldots \overline{V_{1}}\right)^{\eta} T^{\circ}
\end{gathered}
$$

Really, follows from a condition (6) that at $\left(\bar{V}_{k} \ldots \bar{V}_{1}\right)^{\eta+N} T^{\circ}=\left(\bar{V}_{k} \ldots \bar{V}_{1}\right)^{n} T^{\circ}$ any $\mathrm{N}>0$. Let's take $\mathrm{N}>\mathrm{S}\left(\mathrm{V}_{1} \ldots, \mathrm{V}_{\mathrm{k}}\right)$-n.

Owing to the theorem $\left(\bar{V}_{k} \ldots \overline{V_{1}}\right)^{\eta+N} T^{\circ}=\bar{U}_{i=1}^{\bar{k}} V_{i} T^{\circ}$, as was to be shown.

Investigation 2. (criterion of the fact that the plan of early terms is found).

If at $\mathrm{n} \geq 1$ the operator $\bar{V}_{1}$ does not change the plan $\left(\bar{V}_{1} \bar{V}_{2}\right)^{n} T^{\circ}$ or the operator $\bar{V}_{2}$ does not change the plan $\bar{V}_{1}\left(\bar{V}_{2} \bar{V}_{1}\right)^{\eta-1} T^{\circ}$, then the found plan $\left(\bar{V}_{1} \bar{V}_{2}\right)^{\eta} T^{\circ}$ is the plan $\left(V_{1} U V_{2}, T^{\circ}\right)$ - early terms.

Proof. Let, for example 


$$
\bar{V}_{1}\left(\bar{V}_{2} \bar{V}_{1}\right)^{n} T^{\circ}=\left(\overline{V_{2}} \bar{V}_{1}\right)^{n} T^{\circ}
$$

Let's work on both parts of equality the operator:

$$
\begin{aligned}
& \left(\bar{V}_{2} \bar{V}_{1}\right)^{n+1} T^{\circ}=\bar{V}_{2}^{2} \bar{V}_{1}\left(\bar{V}_{2} \bar{V}_{1}\right)^{n+1} T^{\circ}= \\
& \left(\bar{V}_{2} \bar{V}_{1}\right)\left(\bar{V}_{2} \bar{V}_{1}\right)^{n-1} T^{\circ}=\left(\bar{V}_{2} \bar{V}_{1}\right)^{n} T^{\circ}
\end{aligned}
$$

Now it is enough to use the investigation 1.

Definition $5^{\circ}$. The plan of $\mathrm{T}$ we will call $\mathrm{T}^{\circ}$ - admissible along a way $\gamma=\left(\mathrm{x}_{0}, \ldots, \mathrm{x}_{\mathrm{q}}\right)$ if inequalities are carried out

$$
\begin{gathered}
T_{x_{0}}^{\circ} \leq T_{x_{0}}, \\
T_{x_{i}}+\alpha_{x_{i} x_{t+1}}=T_{x_{i}}, \quad(i=1, \ldots, q-1) .
\end{gathered}
$$

Definition $6^{\circ}$. The plan of $\mathrm{T}$ we will call $\mathrm{T}^{\circ}$ - strained along a way $\gamma=\left(\mathrm{h}_{0} \ldots, \mathrm{x}_{\mathrm{q}}\right)$ if equalities are executed

$$
\begin{gathered}
T_{x_{0}}^{\circ}=T_{x_{0}}, \\
T_{x_{i}}+\alpha_{x_{i} x_{t+1}} \leq T_{x_{i}}, \quad(i=1, \ldots, q-1) .
\end{gathered}
$$

Theorem 2. (about tension of the plan of early terms). Equality $T=\bar{V}_{k} \bar{V}_{k-1} \ldots \bar{V}_{1} T^{\circ}$ takes place in only case when when 2 conditions are satisfied:

1) the plan of $\mathrm{T}_{\text {is }} \mathrm{T}^{\circ}$ - admissible for any way $\quad \gamma \in \mathrm{G}\left(\mathrm{V}_{1}, \ldots, \mathrm{V}_{\mathrm{k}}\right)$;

2) for any event $x$ there will be such way $\gamma \in G\left(V_{1}, \ldots, V_{k}\right)$, the plan of $T$ terminating in $\mathrm{x}$, for which is $\mathrm{T}^{\circ}$ - intense.

\section{Algorithm of creation of the plan of early terms (general scheme)}

Let the set of $U$ and directive early terms of 1 be given. Such subsets get out of $U$

$$
\mathrm{V}_{1} \ldots . \mathrm{V}_{\mathrm{v}}
$$

and

$$
\mathrm{W}_{1}, \ldots, \mathrm{W}_{\mu},
$$

that $\mathrm{U}=\mathrm{VUW}$ where $V=\bigcup_{i=1}^{v} V_{i}, W=\bigcup_{i=1}^{\mu} W_{j}$, and the sequences (7), (8) are unilateral. It is expedient to carry out the choice so that $\mathrm{n}=|\mathrm{C}(\mathrm{V}, \mathrm{W})|$ a little. Then it is obvious that $\bar{V}=\bar{V}_{v} \ldots V_{1}, \quad \bar{W}=\bar{W}_{\mu} \ldots \bar{W}_{1}, \quad \bar{U}=(\bar{W} \bar{V})^{n}$.

Applying to the plan consistently operators

$$
\bar{V}_{1}, \ldots, \bar{V}_{v}, \quad \bar{W}_{1}, \ldots, \bar{W}_{\mu}
$$

then again (9) etc. $\mathrm{n}$ of times, we will receive the plan of early terms of $\bar{U}_{1}$. If on some step it turned out that the operator $\bar{V}$ or $\bar{W}$ did not change the plan, the plan of early terms means it is constructed and further iteration is not necessary. Assessment of number of iterations of $n=|C(V, W)| n=$ recommended in this work $m=|W|$, i.e. $n \leq m$.

Perhaps however, to happen that the set of admissible plans is empty. It can occur in the presence of a positive cycle. In this case how many we time applied $\mathrm{V}$ and $\mathrm{W}$ operators, 
terms of a fulfillment of events will increase. To check, it is empty or not the set of admissible plans, are enough to the plan

$$
T=(\bar{W} \bar{V})^{n} l
$$

to apply once operator $\mathrm{V}$. If the $\mathrm{T}$ does not change, then the set is not empty and the plan of early terms of $T$ is constructed. Otherwise, i.e. if at least one $V_{i}$ changes the plan of $T$, there is a positive cycle and admissible plans do not exist.

\section{Examples of application of the general scheme of creation of the plan of early terms}

Let all $\mathrm{x} \in \mathrm{X}$ be numbered by from 1 to $\mathrm{N}$. Let's call an arch $(\mathrm{x}, \mathrm{s})$ a straight line if $\mathrm{x}<\mathrm{y}$, and the return if $x>y$. Let $V$ - a set of direct arches, $W$ - a set of the return arches. We will consider each direct link $(\mathrm{x}, \mathrm{s})$ a separate set of $\mathrm{V}_{\mathrm{i}}$ where $\mathrm{i}$ - number of communication ( $\mathrm{x}$, s). It is obvious that the sequence of $V_{i}, V_{2} \ldots, V_{M}$ where $M$ - the number of direct connections, is unilateral. Therefore

$$
\bar{V}=\bar{V}_{M} \ldots, \bar{V}_{2} \bar{V}_{1}
$$

Let's consider in the same way that $\mathrm{W}$ is broken into One element sets of $\mathrm{W}_{1}$., $\mathrm{W}_{\mathrm{k}}$. It is obvious that $\bar{W}=\bar{W}_{k} \ldots, \bar{W}_{2} \bar{W}_{1}$.

According to the theorem 1:

$$
(\bar{W} \bar{V})^{n}=\bar{U}
$$

where $\mathrm{n}$ - the number of events in which feedback terminate.

Let to some extent the great number of $\mathrm{X}$ be broken into $\mathrm{X}_{1} \ldots, \mathrm{X}_{\mathrm{N}}$.

Let's note that in work they are interpreted as sets of knots of the networks corresponding to objects of a multi-object complex.

Let's designate through $\mathrm{F}_{\mathrm{i}}$, a set of the communications beginning and terminating in $\mathrm{X}_{\mathrm{i}}$. Such communications we will call internal.

For $\mathrm{i}<\mathrm{N}$ we will designate $\mathrm{N}$ through ${ }_{\mathrm{P}}$, a set of the communications beginning in a set of $\mathrm{X}_{\mathrm{i}}$ and terminating in sets with big numbers. We will call such communications external straight lines.

For $\mathrm{i}>1$ we will designate through $\mathrm{H}_{\mathrm{i}}$ a set of the communications beginning in a set of $\mathrm{X}_{\mathrm{i}}$ and terminating in sets with smaller numbers. We will call such communications the external return.

Let's put

$$
\begin{gathered}
\mathrm{V}_{\mathrm{i}}=\mathrm{F}_{\mathrm{i}} \cup \mathrm{P}_{\mathrm{i}}(\mathrm{i}=1, \ldots, \mathrm{N}-1), \\
\mathrm{Wi}=\mathrm{F}_{\mathrm{N}-\mathrm{i}} \cup \mathrm{H}_{\mathrm{N}-\mathrm{i}}(\mathrm{i}==0,1, \ldots, \mathrm{N}-2) .
\end{gathered}
$$

It is easy to show that the sequences of $\mathrm{V}_{\mathrm{i}}, \ldots, \mathrm{V}_{\mathrm{N}-1}$ and $\mathrm{W}_{1}, \ldots, \mathrm{W}_{\mathrm{N}-1}$ are unilateral. Therefore, according to a lemma 3 and the theorem $1 \quad \bar{V}=\bar{V}_{N-1} \ldots \bar{V}_{1}, \quad \bar{W}=\bar{W}_{N-1} \ldots \bar{W}_{1}$, where $V=\bigcup_{i=1}^{N-1} V_{i}, W=\bigcup_{i=1}^{N-1} W_{i}$,

According to the theorem 1 we have:

$$
(\bar{W} \bar{V})^{n}=\overline{W U V}
$$

where $\mathrm{n}$ does not surpass number of final states for external feedback. 
Algorithms of search of plans of late terms essentially do not differ from the algorithms given in sections 2 and 3 therefore there is no need to stop on it once again.

After finding of plans of $\mathrm{T}^{*}$ and $\mathrm{T}^{*}$ for the analysis of a set of admissible plans it is necessary to find the general reserves of R:

$$
\mathrm{F}=\mathrm{T}^{*}-\mathrm{T} *
$$

and also private reserves:

$$
r_{x}=\min _{y}\left\{\left(T_{*}\right)_{y}-\alpha_{x y}\right\}-\left(T_{*}\right)_{y}
$$

\section{Conclusion}

In conclusion we will note that the device offered in work not only gives wider and systematized view of stream algorithms on the basis of OSM, but also allows to receive numerous modifications of these algorithms, using concrete information on structure of a set of $U$.

\section{References}

1. V.E. Belousov, O.Yu. Karchevsky, Messenger of VSU, Series: System analysis and information technologies 1, 77-81 (2017)

2. V.E. Belousov, The Bulletin of VSU. Series: System analysis and information technologies 3, 124-129 (2017)

3. V. Belousov, T. Averina, P. Kurochka, AICT2017 conference proceedings, Scientific edition 1, CFP1756H-PRT, 164-169 (2017)

4. S. Khaykin, Neural networks: full course, 2nd edition, The lane with English (Williams publishing house, Moscow, 2006) 